\title{
Covid-19: a puzzle with many missing pieces
}

\author{
Better information on epidemiology, pathogenesis, and treatments are urgent priorities
}

\author{
Pauline Vetter physician ${ }^{12}$, Isabella Eckerle professor ${ }^{13}$, Laurent Kaiser professor $^{123}$ \\ ${ }^{1}$ Geneva Centre for Emerging Viral Diseases, Geneva University Hospitals, 1211 Geneva 14, Switzerland; ${ }^{2}$ Division of Infectious Diseases, Geneva \\ University Hospitals, Geneva, Switzerland; ${ }^{3}$ University of Geneva, Faculty of Medicine, 1205 Geneva, Switzerland
}

By 15 February 2020, 51800 cases of the novel coronavirus disease (formerly known as 2019-nCoV and renamed covid-19), including more than 1600 deaths, had been confirmed in China, mainly in Hubei province. A further 526 laboratory confirmed cases have been reported across 25 other countries. ${ }^{1}$ As is usual in the early phase of a disease outbreak, the alarm was raised as a result of the most severe cases, and the first reports describe severe pneumonia in patients admitted to hospital. ${ }^{2}$

In a linked paper, Xu and colleagues (doi:10.1136/bmj.m606) report a case series of 62 patients (median age 41 years) admitted to hospital in the Zhejiang province with laboratory confirmed infection with severe acute respiratory syndrome coronavirus-2 (SARS-CoV-2), the virus responsible for covid-19. ${ }^{3}$ All the patients presented with respiratory symptoms, fever or flu-like illness, or both, and all had travelled to Wuhan or been in contact with a patient with confirmed covid-19 while staying in Wuhan. All but one had radiologically confirmed pneumonia, but only one patient was subsequently admitted to an intensive care unit and none has died, similar to other reports describing less severe disease. $^{45}$

Among cases reported to the World Health Organization, 15\% are severe, $3 \%$ are critical, and $82 \%$ are mild (press conference WHO, 7 February 2020. https://twitter.com/WHO/status/ 1225797786903277568). The estimated overall case fatality rate is around $2 \%$ but outside of Hubei province the figure is around 0.05 or less, not so far from the mortality observed with seasonal influenza. We should not be lulled into inaction by this low fatality rate, however: no cross protection by a common human coronavirus infection is expected and SARS-CoV-2 can theoretically infect any one of us. As with influenza, the complications from covid-19 target particularly older people, but the disease can also strike unpredictably in younger age groups.

A lower risk of complications is good news for individuals, but a mild disease presentation allows a larger chain of transmission through populations. A rapid understanding of the spectrum of the disease and the extent of unrecognised infections is essential. Beyond small series, such as the one by $\mathrm{Xu}$ and colleagues, we need more detailed information on the epidemiology at country level. Importantly, more than two months after the first observed cases, we still have a limited understanding of the epidemiological trajectory of this infection. WHO has reported the dates of diagnosis, but this is not enough. Public release of all available data on the timing of symptom onset should be a top priority. Wider testing for covid-19 among patients with uncomplicated upper respiratory tract infections should also be considered.

So far, sustained chains of transmission have not been reported outside Asia. It is not yet clear why. Possible but speculative explanations include effective containment, inefficient transmission, poor reporting owing to lack of molecular testing capacity in some low income countries, genetic factors encouraging transmission within Asian populations, and specific environmental conditions in Hubei province and mainland China. The genome data available so far show no unexpected mutation rate or signs of adaptation, so viral factors are unlikely to be contributing to the differences observed between China and the rest of the world.

Investigation of the pathogenesis of the disease, viral kinetics, and site of replication is also essential. This is not only critical for infection control but informs the design of antiviral interventions. SARS-CoV-2 has been isolated in saliva, ${ }^{6}$ nasopharynx, and lower respiratory tract samples. ${ }^{7}$ Viral RNA has been found in the plasma of $15 \%$ of the most severely affected patients, ${ }^{2}$ and viral detection in stool raises the possibility of faecal transmission. ${ }^{8}$ The duration and extent of viral shedding are yet to be quantified. Other unanswered questions include the rate of bacterial complications, influenza and other viral coinfections, and the physiopathology of clinical infection within the lung. The lack of lung biopsies or post mortem samples contributes to an incomplete understanding of the pathogenesis of this infection.

\section{Treatment horizon}

Most patients described in Xu and colleagues' case series had unproved treatments. A range of different drugs and molecules are currently under evaluation. Remedesevir, a nucleotide analogue, is active against covid- 19 in vitro ${ }^{9}$ and has been shown to be safe in Ebola trials. ${ }^{10}$ HIV antiproteases, with or without 
inhaled interferon, are currently being tested against the Middle East respiratory syndrome coronavirus (MERS-CoV).

Evaluations during the 2002-03 SARS outbreak were, however, inconclusive.

Surprisingly, anti-influenza drugs umifenovir and oseltamivir are also under investigation, despite the lack of biological rationale. Monoclonal antibodies as passive prophylactic or therapeutic immunotherapy are an attractive option, although antibodies used to treat respiratory syncytial virus or influenza have not been successful so far. ${ }^{11}{ }^{12}$ Steroids and methylprednisolone seem to be used frequently, but they prolong viral shedding in patients with MERS-CoV and WHO advises against their use in covid-19, except for patients with an associated acute respiratory distress syndrome. Other interventions under evaluation include hydroxychloroquine, vitamin $\mathrm{C}$, and elements of Chinese medicine. With any antiviral treatments, timely administration before complications develop will be crucial.

Randomised controlled trials of the most promising treatments are a leading priority, and, hopefully, the road to an effective treatment and vaccine will not be too long. But despite the urgency generated by the emergence of a new disease, health providers and researchers must maintain a rigorous evidence based approach underpinned by sound ethical rules. "First, do no harm" must still be the guiding principle.

Competing interests: We have read and understood BMJ policy on declaration of interests and declare that we have no competing interests.
Provenance and peer review: Commissioned; not peer reviewed.

1 Coronavirus disease. 2019 (COVID-19): situation report-26, 15 February 2020. Geneva: World Health Organization, 2020 (https://www.who.int/docs/default-source/coronaviruse/ situation-reports/20200215-sitrep-26-covid-19.pdf?sfvrsn=a4cc6787_2).

2 Huang C, Wang Y, Li X, etal . Clinical features of patients infected with 2019 novel coronavirus in Wuhan. Lancet, 202010.1016/S0140-6736(20)30183-5.

3 Xu X-W, Wu X-X, Jiang X-G, etal . Clinical findings in a group of patients infected with the 2019 novel coronavirus (SARS-Cov-2) outside of Wuhan, China: retrospective case series. BMJ 2020;368:m606.

4 Chan JF, Yuan S, Kok KH, etal . A familial cluster of pneumonia associated with the 2019 novel coronavirus indicating person-to-person transmission: a study of a family cluster. Lancet 2020;395:514-23. 10.1016/S0140-6736(20)30154-9 31986261

5 Pongpirul WA, Pongpirul K, Ratnarathon AC, Prasithsirikul W. Journey of a Thai Taxi Driver and Novel Coronavirus. N Engl J Med 2020. 10.1056/NEJMc2001621 32050060

6 To KK, Tsang OT, Chik-Yan Yip C, etal . Consistent detection of 2019 novel coronavirus in saliva. Clin Infect Dis 2020;ciaa149. 10.1093/cid/ciaa149 32047895

7 Zhu N, Zhang D, Wang W, etal. China Novel Coronavirus Investigating and Research Team. A Novel Coronavirus from Patients with Pneumonia in China, 2019. N Engl J Med 2020. 10.1056/NEJMoa2001017 31978945

8 Zhang H, Kang ZJ, Gong HY, etal . The digestive system is a potential route of 2019 $\mathrm{nCoV}$ infection: a bioinformatics analysis based on single-cell transcriptomes. BioRxiv 927806 [Preprint]. 2020. 10.1101/2020.01.30

9 Wang M, Cao R, Zhang L, etal . Remdesivir and chloroquine effectively inhibit the recently emerged novel coronavirus (2019-nCoV) in vitro. Cell Res 2020. 10.1038/s41422-020-0282-0 32020029

10 Mulangu S, Dodd LE, Davey RTJr, etal. PALM Writing GroupPALM Consortium Study Team. A Randomized, Controlled Trial of Ebola Virus Disease Therapeutics. N Engl J Med 2019;381:2293-303. 10.1056/NEJMoa1910993 31774950

11 Alansari K, Toaimah FH, Almatar DH, El Tatawy LA, Davidson BL, Qusad MIM. Monoclonal Antibody Treatment of RSV Bronchiolitis in Young Infants: A Randomized Trial. Pediatrics 2019;143:pii. 10.1542/peds.2018-2308 30760509

12 Beigel JH. Polyclonal and monoclonal antibodies for the treatment of influenza. Curr Opin Infect Dis 2018;31:527-34. 10.1097/QCO.0000000000000499 30299360

Published by the BMJ Publishing Group Limited. For permission to use (where not already granted under a licence) please go to http://group.bmj.com/group/rights-licensing/ permissions 